\title{
Congruence constructs as mediators of stereotypic image perceptions' effect on student volunteering intention
}

\section{Jörg Lindenmeier ${ }^{1}[$ ( $)$ Christian Arnold ${ }^{2} \cdot$ Adnan Zogaj $^{3} \cdot$ Dieter K. Tscheulin $^{3}$}

Received: 29 October 2020 / Accepted: 12 March 2021 / Published online: 9 April 2021

(C) The Author(s) 2021

\begin{abstract}
This study aims to analyze the effects of ideal and actual self-congruence and functional congruence on the volunteering intentions of university students. The empirical analysis is based on a sample of 735 students from universities in southwestern Germany. The current paper shows that stereotypic image perceptions (i.e., perceived warmth and competence) represent antecedents of the considered congruence constructs. Moreover, the study shows that actual self-congruence and functional congruence mediate the effect of perceived warmth and competence on the intention to volunteer. Ideal self-congruence did not mediate the effect of stereotypical image perceptions, nor did it have a direct effect on the willingness to take voluntary action. The study offers practical recommendations for nonprofit organizations, as well as avenues for future research based on its empirical findings.
\end{abstract}

Keywords Self-congruity $\cdot$ Volunteering $\cdot$ Germany $\cdot$ Stereotypes

\section{Introduction}

The commitment of volunteers is an invaluable resource that has a positive social impact and contributes to societal cohesion. Volunteers work in various fields

Jörg Lindenmeier

joerg.lindenmeier@vwl.uni-freiburg.de

Christian Arnold

carnold@ist-hochschule.de

Adnan Zogaj

adnan.zogaj@vwl.uni-freiburg.de

Dieter K. Tscheulin

dieter.tscheulin@vwl.uni-freiburg.de

1 University of Freiburg, Wilhelmstr. 1b, 79085 Freiburg, Germany

2 IST University of Applied Sciences, Erkrather Straße 220 a-c, 40233 Düsseldorf, Germany

3 University of Freiburg, Rempartstr. 16, 79085 Freiburg, Germany 
of activity with nonprofit organizations and thereby support the charitable purposes of these organizations. Furthermore, previous studies show that volunteering can also have a positive effect on volunteers (Cicognani et al., 2015; Pan, 2012; Yeung et al., 2018). A significant proportion of the population in Western countries is engaged in voluntary work. In 2014 (OECD, n.d.), 44\% of the US population engaged in voluntary work. This figure was $32 \%$ in Germany and $29 \%$ in the United Kingdom. In Southern European countries and Asia, the figure was slightly lower (for instance, $18 \%$ in Italy and 23\% in South Korea). Significantly lower proportions of the population in Eastern Europe work as volunteers (for instance, $9 \%$ in Hungary).

Since nonprofit organizations are less able or sometimes even unable to finance themselves as profit-oriented companies through market revenues, they are more strongly confronted with problems related to scarce resources. Wicker and Breuer (2011) show that effectively acquiring and managing volunteers constitutes one means to address resource scarcity. University students are a particularly interesting group of potential volunteers who nonprofit organizations can target (Francis, 2011). University students usually have more free time than, for example, fully employed individuals with children. University students can organize their time more flexibly than those from the working population, for instance, due to having extensive time outside of class hours. Furthermore, to ensure a stable support base and replace retiring senior volunteers or other volunteers who leave organizations, the acquisition of young volunteers is crucial for many nonprofit organizations. In addition, in a study focusing on the British healthcare sector, Chatwin and Ackers (2016) show that volunteers in certain activity fields are particularly recruited from younger age groups. Accordingly, the relevance of attracting young volunteers is obvious, and the present study therefore aims to explain university students' volunteering inclinations.

Hustinx, Cnaan, and Handy (2010a) state that the term 'volunteering' cannot be easily defined. As highlighted by Cnaan et al. (1996), Jenner (1982, p. 30) provides the following definition of 'pure' volunteer engagement: 'A volunteer was defined as a person who, out of free will and without wages, works for a notfor-profit organization which is formally organized and has as its purpose service to someone or something other than is membership.' According to Cnaan et al. (1996), however, it is also necessary to distinguish different forms of 'impure' volunteering. In line with this notion, the following four differentiation dimensions have been identified: (1) voluntariness of the voluntary commitment (i.e., from 'free will' to 'an obligation to volunteer'), (2) existence and type of compensation (i.e., from 'none' to 'stipend/low pay'), (3) closeness with beneficiaries (i.e., from 'helping strangers/others' to '(also) helping oneself'), and (4) degree of formalization (i.e., 'formal volunteering in a nonprofit organization' vs. 'informal, self-organized types of volunteering'). Student volunteering can generally take place in both 'pure' and 'impure' forms. For example, service learning integrated into a degree program's curriculum can be linked to a commitment to volunteerism among students. In addition, financial compensation for students who volunteer may be available (e.g., stipends). The present study primarily focuses on 'pure' voluntary work. 
20Different theoretical frameworks and approaches concerning the topic of volunteering have been developed. For example, Musick and Wilson (2007) underscore the significance of the so-called 'resource model,' which states that human, social, and cultural capital are determinants of volunteerism. Hustinx, Cnaan, and Handy (2010a) point out that the phenomenon of volunteering is a field of research addressed by several academic disciplines. Political science highlights the significance of volunteering for citizenship and democracy (e.g., Eliasoph, 2013). Sociological research focuses on aspects such as the relevance of individual socialization (e.g., Janoski et al., 1998) and culture (Hustinx, Handy, Cnaan, Brudney, et al., 2010 b) to volunteering. Moreover, the 'dominant status model' shows that an individual's economic or social status is a determinant of his or her volunteering habits (Smith, 1994). In addition to these approaches to the research field, economic approaches have gained particular importance. As in the psychological approaches discussed below, the main question here concerns why volunteers become involved. From the classical economic perspective, volunteering seems irrational at first. However, on the one hand, these economic approaches view volunteering as an impure altruistic behavior and assume that egoistic and altruistic motives drive volunteering behavior (Burns et al., 2006). The decision to volunteer is based on a cost-benefit calculation that weighs up the costs (i.e., time effort) and benefits of volunteering (Handy \& Mook, 2011). According to the 'private benefit model,' a desire to experience warm feelings (e.g., Andreoni et al., 1996; Lilley \& Slonim, 2014) can motivate engagement in volunteering. Reciprocity considerations or the acquisition of professional skills are arguments for volunteering from the perspective of the socalled 'investment model' (e.g., Menchik \& Weisbrod, 1987). On the other hand, economists also model volunteering as a public good problem (e.g., Hackl et al., 2012). Psychological approaches consider volunteering as a kind of prosocial behavior that can be explained by emotional processes (see, e.g., Lindenmeier, 2014) or variations in personality traits (Ackermann, 2019), among other factors.

A significant proportion of previously published papers on volunteering among students is based on the named psychological approach. While some of these papers mainly focus on explaining the drivers behind students' volunteering intentions (e.g., Francis, 2011; Smith et al., 2010), others are more concerned with the efficient organization of student volunteering (e.g., Gazley et al., 2012; Haski-Leventhal et al., 2020). Furthermore, works such as that by Shields (2009) highlight the importance of marketing in increasing the number of young volunteers. Building on this research, a psychological approach on which the development of effective marketing measures for the acquisition of student volunteers can be based is Sirgy's (1986) self-congruity theory (Sirgy, 1986). This theory considers the idea that individuals compare their self-concept to the images of brands or organizations. Perceptions of self-congruence are the result of this cognitive comparison process. Previous consumer research has shown that consumers are more inclined to make purchases from a brand if they perceive a higher level of actual or ideal self-congruence with the brand (Davis \& Lang, 2013). The distinctive contribution of self-congruity theory is that the symbolic value of a brand is considered in addition to its functional benefits. Since younger individuals interact heavily with their peer groups (see, e.g., Lee, 2010) and thus pay particular attention to their self-image, a positive effect of 
self-congruence on purchasing behavior could be empirically demonstrated in this consumer group (e.g., Lu \& Xu, 2015). Considering this rationale, this paper analyzes whether perceived self-congruity also affects students' volunteering intentions.

Previous nonprofit marketing research has already used the congruence rationale. One stream of research has examined the effect of perceived congruence in a causerelated marketing (CRM) context. For example, Kuo and Rice (2015) show that the fit between the sponsored cause and the sponsoring company has a positive effect on the effectiveness of CRM campaigns. In addition, a closely related line of research addresses cobranding alliances of for-profit and not-for-profit organizations. Again, previous research such as that by Dickinson and Barker (2007) reveals that a higher level of perceived brand congruence is crucial to the success of these alliances. Other papers examine the effects of variations in value congruence on prosocial behaviors such as donating to charities. These papers show that the fit of potential donor values and nonprofit organizational values (i.e., so-called person-organization fit) can stimulate donation or volunteering behavior (Bahat, 2020; van Dijk et al., 2019).

A small number of nonprofit research papers explicitly consider Sirgy's (1986) selfcongruence construct as a driver of prosocial behaviors such as donating or volunteering. For example, Bennett (2009) shows that image congruence is a decisive factor in explaining donor switching between nonprofit organizations and charitable causes. In another paper, Zogaj et al. (2020) show that ideal and functional self-congruence have a direct effect on donation intentions. Moreover, the authors show that the effect of actual self-congruence is contingent on individuals' issue involvement. As a further example, Beerli et al. (2004) find differences between the self-concepts of volunteers working for different charity brands. Moreover, Stephenson and Bell's (2014) study reveals that the probability of alumni not donating to their alma mater rises as their perceptions of incongruity between the university's image and the alumni's self-image increases. In their seminal paper, Randle and Dolnicar (2011) reveal that potential volunteers' preference for a specific nonprofit organization is contingent on self-congruity. The authors' empirical study is based on a rather fine-grained comparison of single question items of a brand-personality scale (e.g., 'honest,' 'outdoorsy,' or 'heroic'). Apart from significance tests, the authors do not conduct any elaborate multivariate data analyses. Emens et al. (2014) delineate a conceptual model in which actual and ideal self-congruence are considered mediators of the relationship between imagerelated constructs and volunteering intentions. In their empirical study, however, the authors do not validate the hypothesized mediation effects.

To contribute to existing nonprofit marketing research, this study uses a sample of university students to analyze how perceived self-congruence affects the willingness to volunteer. As a first research contribution and in contrast to previous research that solely considers a rather unspecific congruity construct (i.e., Randle \& Dolnicar, 2011), this study explicitly distinguishes between actual and ideal self-congruence as drivers of volunteering intentions and can therefore offer more detailed insights into the functioning of the congruence mechanism. As a second contribution, functional congruence is considered as a further determinant of volunteering behavior. In the present research, functional congruency is based on potential volunteers' perceptions of nonprofit organizations' effectiveness and efficiency. As a third contribution to self-congruence research that extends beyond nonprofit management research, 
this study considers stereotypic image perceptions as antecedents of actual and ideal self-congruence and functional congruence. More precisely, based on the stereotype content model (Fiske et al., 2002), this study considers the perceived warmth and perceived competence of nonprofit organizations as antecedents of self-congruence. As a fourth contribution to research, this paper empirically validates the mediation effects of actual and ideal self-congruence in the context of the causal relationship between stereotypic image perceptions and volunteering intentions, which Emens et al. (2014) conceptualize but do not test.

\section{Conceptual considerations}

\subsection{Congruence constructs}

A person's self-concept is the sum of thoughts and emotions regarding himself or herself (Rosenberg, 1979). Hence, the self-concept is the image a person has about himself or herself (Hong \& Zinkhan, 1995). Self-concept has similarities to an individual's identity, for which Crocetti, Jahromi, Meeus (2012) could demonstrate an effect on civic engagement for adolescents. Contrary to identity, self-congruence is based on a cognitive comparison process and describes the extent to which one's own self-concept matches the self-concept of another individual or entity (e.g., nonprofit organizations) (see, for instance, Ahn et al., 2013; Sirgy, Johar, Samli, \& Claiborne, 1991). Gilmore's (1919) concept of animism is the theoretical basis of selfcongruence research. According to this theory, people personify objects to be able to interact with them. Gilmore's idea of anthropomorphism (that is, the transfer of human characteristics to nonhuman objects) makes it possible to compare oneself to another inanimate object (Stinnett et al., 2013).

Research distinguishes between the actual and ideal dimensions of self-congruence (Malär et al., 2011). If a person compares another person's image to his or her actual self-concept, this is referred to as actual self-congruence. Conversely, if someone compares another person's image to his or her ideal self-concept, this is referred to as ideal self-congruence (Malär et al., 2011). The effect of self-congruence on behavior can be explained based on two motives (Claiborne \& Sirgy, 2015; Sirgy, 1982). First, the self-consistency motive, for instance, leads consumers to buy products or branded goods whose self-concept matches their actual self-concept (Sirgy, 1982). This motivational process is based on individuals' need to strengthen their own self-image by approaching individuals and behaviors that reflect how they perceive themselves (Liberman et al., 1999). Second, the need for self-enhancement motivates individuals to consume from brands that match their ideal self-concept (Claiborne \& Sirgy, 2015). Based on this motive, subjects aim to increase their selfesteem by closing the gap between themselves and their ideal selves (Malär et al., 2011).

Functional congruence is based on functional characteristics and reflects the matching of expected and perceived functional characteristics (Choi \& Reid, 2016; Johar \& Sirgy, 1991). Functional characteristics can vary across contexts. For example, in a food industry context, product attributes such as flavor and natural content 
are examples of functional product attributes (Choi \& Reid, 2016). Hence, functional congruence is based on individuals' utilitarian needs, which can be satisfied by the use of high-quality products (Batra \& Ahtola, 1991). If this concept is applied to voluntary organizations, the utilitarian (i.e., functional) attributes of voluntary organizations must be defined. Willems et al. (2016) develop a measure of organizational reputation that comprises nonprofit organizations' functional attributes that can be used to measure functional congruence based on performance-related items (Zogaj et al., 2020). Thus, also in line with other nonprofit research (see, for instance, Kirk \& Beth Nolan, 2010), this study assumes that the concept of functional congruence reflects the degree of nonprofit organizations' effectiveness and efficiency.

Previous research has revealed positive effects of congruence constructs on consumer behavior. For instance, Sirgy et al. (1991) showed that store loyalty, attitudes toward retail stores, and purchase intentions are functions of self-congruence and functional congruence. Kressmann et al. (2006) reveal that both self-congruence and functional congruence influence brand loyalty. Hung and Petrick (2012) analyze the congruence hypotheses for the tourism sector and showed that self-congruence and functional congruence have positive effects on travel consumption. More recent studies have also confirmed the effects of congruence (Choi \& Reid, 2016; Su \& Reynolds, 2017; Zogaj et al., 2021).

The positive effect of self-congruence and functional congruence has also been supported in the nonprofit context. Zogaj et al. (2020) confirm that ideal self-congruence has a predominantly positive effect on donor behavior, while actual selfcongruence only positively affects donor behavior if donors exhibit high degrees of issue involvement. The authors argue that individuals exhibiting low involvement especially aim to enhance their self-concept by donating, which is why they support organizations that match their ideal self-congruence. On the other hand, highly involved donors deal more strongly with an organization's focuses and aim to exhibit their personal values by donating. Moreover, the authors confirm that functional congruence positively affects donor behavior, as donors want organizations to use financial resources effectively and to reach their goals.

Thus, based on previous nonprofit marketing research (e.g., Stephenson \& Yerger, 2014; Zogaj et al., 2020), it can be hypothesized that actual and ideal selfcongruence as well as functional congruence have positive effects on volunteering behavior. The motives that underlie the effects of the congruence constructs on helping behavior (i.e., self-verification, self-enhancement, and utilitarian benefits) find support in previous research. For example, Ottoni-Wilhelm (2017) demonstrate that prosocial behavior is driven by self-verification and self-enhancement, and Clary et al. (1992) indicated that volunteering has a self-enhancement function of improving an individual's self-image. This view is implicitly based on the idea that individuals seek to more closely emulate an ideal self-concept. Finally, researchers such as Zogaj et al. (2020) have confirmed that utilitarian benefits positively influence prosocial behavior. Therefore, hypotheses $\mathrm{H}_{1 \mathrm{a}}, \mathrm{H}_{1 \mathrm{~b}}$, and $\mathrm{H}_{1 \mathrm{c}}$ are as follows:

$\mathbf{H}_{1 \mathbf{a}}$ Actual self-congruence has a positive effect on volunteering intentions.

$\mathbf{H}_{\mathbf{1 b}}$ Ideal self-congruence has a positive effect on volunteering intentions.

$\mathbf{H}_{1 \mathbf{c}}$ Functional congruence has a positive effect on volunteering intentions. 
Studies investigating the effects of congruence should recognize that actual and ideal self-congruence evolve subconsciously and that self-congruence is formed before individuals evaluate the functional characteristics of which they are more aware. This sequence of the perception formation process results in a bias because, ceteris paribus, subjects with stronger self-congruence perceptions evaluate functional congruence more positively. Accordingly, empirical research shows that selfcongruence has a positive effect on functional congruence (Choi \& Reid, 2016; Kressmann et al., 2006). Hence, this study considers a positive causal relationship between both self-congruence constructs and functional congruence.

\subsection{Stereotypic image perceptions}

Social judgment and human decision-making processes are based on complex information, and individuals use stereotypes to 'deal' with this complexity. Social judgment theory states that stereotypes simplify the ways that individuals view other persons or social groups and thus help them navigate various situations in their daily lives (Bodenhausen, 1990). As a component of social judgment theory, the stereotype content model (Fiske et al., 2002) states that perceived warmth and competence are the most important interpersonal and intergroup stereotypes.

According to Baghi and Gabrielli (2013), the stereotype 'warmth' is associated with perceptions regarding whether and to what extent another person is focused on others and adheres to moral norms. 'Competence,' as the other major stereotype, pertains to the assessment of other persons' capacities to effectively achieve certain goals. In line with these definitions, measurement scales that assess warmth (competence) include items such as 'warm,' 'kind,' and 'generous' ('competent,' 'effective,' and 'efficient'). According to Cuddy et al. (2008), information stimuli about social-structural relationships (that is, a person's social status and competitive relations between persons) are essential for the formation of perceptions of warmth and competence. In concrete terms, this assumption suggests that individuals should perceive social groups with high social status as more competent than social groups with low social status. Furthermore, noncompetitive social groups are perceived to be warmer than competitive social groups. Authors such as Caprariello et al. (2009) state that different combinations of warmth and competence stereotypes may elicit specific emotions. A combination of high warmth and high competence (low warmth and low competence) should result in felt aspiration (felt contempt). An ambivalent combination of low warmth and high competence (high warmth and low competence) arouses the emotion of envy (pity).

In line with animism theory and the anthropomorphism concept mentioned in the preceding section, Aaker et al. (2010) state that consumers use stereotypes when forming judgments about nonprofit or for-profit organizations. This means that consumers transfer human characteristics to organizations such as nonprofit organizations. Considering this image transfer, Aaker et al. (2010) state that the stereotypical perceptions of organizations vary with their sponsorship status (i.e., nonprofit vs. for-profit sponsorship status). In line with this notion, Drevs et al.'s (2014) study indicates that nonprofit (for-profit) organizations are seen as being more (less) warm and less (more) competent. Moreover, the authors show that stereotypic perceptions 
of an organization have an impact on the constructs that are closely related to actual consumer behavior, namely, quality beliefs. This finding is in line with the research of Cuddy and colleagues (see, for instance, Cuddy et al., 2008), which shows that warmth and competence stereotypes are associated with specific behavioral correlates. The so-called 'behavior from intergroup affect and stereotypes' (BIAS) map (see, for instance, Fiske, 2015), which uses the stereotype content model as its basis, predicts that variations in warmth result in active reactions (that is, active facilitation vs. active harm). Different types of prosocial behavior, such as volunteering behavior investigated here, represent typical examples of active facilitation. Conversely, varying competence judgments should result in variations in passive behavioral reactions (that is, passive facilitation vs. passive harm). Associating is a form of passive facilitation, and this kind of behavior resembles volunteering that necessitates a long-term commitment to a nonprofit organization (Aydinli et al., 2016).

As mentioned above, ideal self-congruence represents the matching of, for instance, a brand's or an organization's image with an individual's ideal self-concept (Malär et al., 2011). Certain commercial brands (for instance, Nike and Apple) are especially popular among consumers, and thus many consumers seek to experience some the glamour attributed to these brands by purchasing their products. The same may be true for popular nonprofit brands such as Greenpeace and UNICEF (see Boenigk \& Becker's, 2016 nonprofit brand ranking), and individuals are more likely to volunteer for these organizations. According to Cuddy et al. (2008), a combination of perceived warmth and competence results in feelings of admiration toward the perceived object, such as a nonprofit brand. Based on this notion, this study assumes a positive effect of the perceived competence and warmth of nonprofit organizations on potential volunteers' ideal self-congruence.

Actual self-congruence is defined as the fit between a consumer's self-image and a brand's or company's image. This study assumes that individuals, on average, evaluate their personality more positively than it actually is. This notion is in line with previous research from authors such as Boseovski (2010) and Thomsen et al. (2014) that reveals a positive bias in the evaluation of one's own personality. Since according to this bias, one can assume that individuals perceive themselves to be warmer and more competent, the perceived warmth and competence of nonprofit organizations should have a positive effect on actual self-congruence.

As mentioned above, functional congruence relates to the functional characteristics of products (Choi \& Reid, 2016) and to the satisfaction of utilitarian needs (Batra \& Ahtola, 1991). Transferred to the nonprofit sector, this study associates functional congruence with mission fulfillment. In this context, it is evident that perceived competence must be closely related to organizational efficiency and effectiveness. Thus, perceived competence should have a positive effect on functional congruence. Therefore, since the congruence constructs should transmit the effect of stereotype image perceptions to volunteering intentions, hypothesis $\mathrm{H} 2$ is as follows:

H2. The congruence constructs mediate the effects of perceived warmth and perceived competence on volunteering intentions. 
Figure 1 provides a simplified overview of the model constructs and of the assumed direct (i.e., hypotheses $\mathrm{H}_{1 \mathrm{a}}-\mathrm{H}_{1 \mathrm{c}}$ ) and mediating effects (i.e., hypothesis $\mathrm{H}_{2}$ ) of the three considered congruence constructs.

\section{Data collection}

To test the hypotheses, 735 students at three universities in southwestern Germany were surveyed. The survey was conducted at a large public university, a public university of applied sciences, and a private university of applied sciences. The questionnaires were distributed during lectures, during which the students were given sufficient time to complete the two-page paper-and-pencil questionnaire. The study participants were informed that the aim of the study was to determine which factors influence the willingness to engage in long-term volunteer work.

Reflective measurement scales from existing research were utilized to measure perceived warmth and competence (Drevs et al., 2014), actual and ideal self-congruence (Malär et al., 2011; Sirgy, Grewal, Mangleburg, Park, Chon, Claiborne et al., 1997) and functional congruence (Choi \& Reid, 2016; Sirgy et al., 1991). We developed the functional congruency scale further based on a scale created by Willems et al. (2016) that measures the reputations of nonprofit organizations. To assess volunteering intentions, we used typical behavioral intention question items. Appendix Table 4 presents the measurement scales for all latent constructs included in our theoretical model, which is shown in Fig. 1. The appendix illustrates the dimensions of the stereotypical
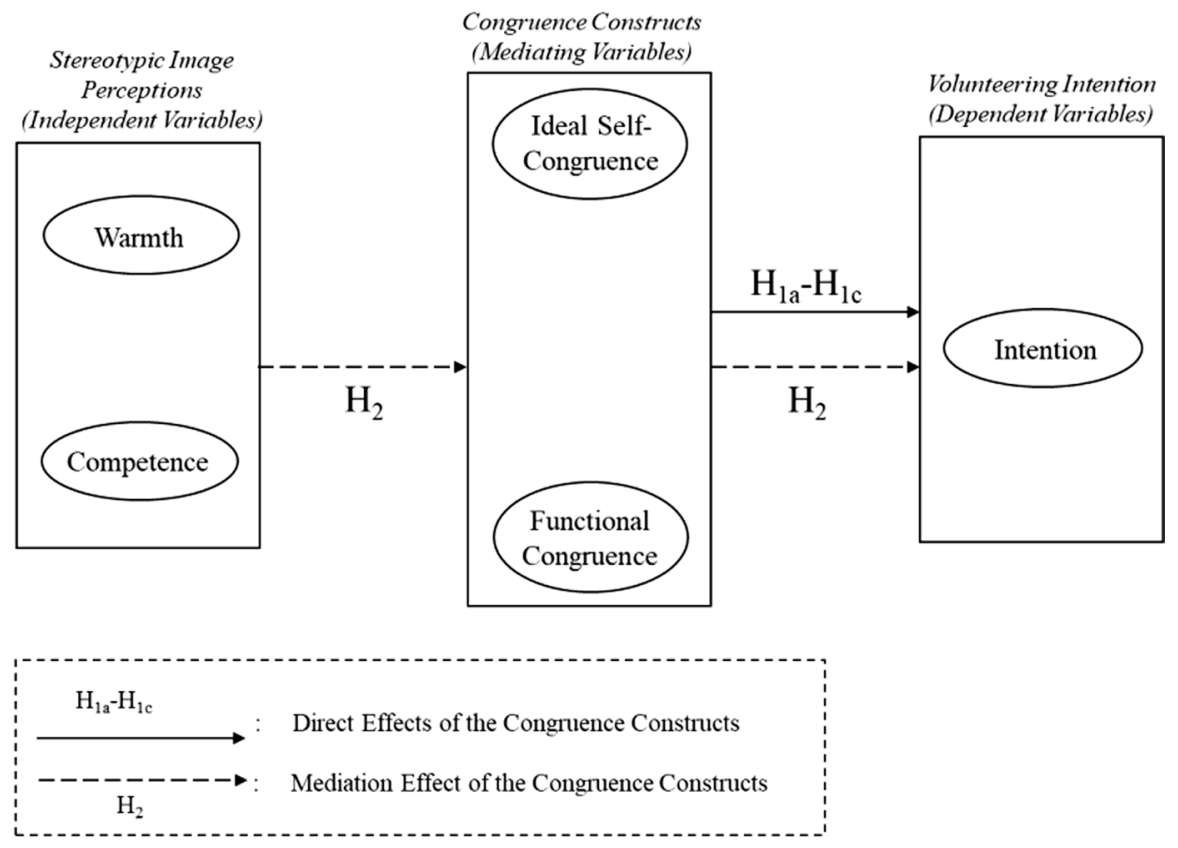

Fig. 1 Conceptual model (Hypotheses) 
image perceptions and congruence constructs along with the corresponding wording of the question items and response scales.

To guarantee external validity, subjects were randomly assigned to one of three German nonprofit organizations $(n=\{244,246,245\})$. For each group, a different but widely known nonprofit organization was referenced - namely, Caritas, the German Section of Amnesty International, and the German Red Cross. To ensure that the respondents were able to evaluate the organization in question, only individuals who confirmed having at least one relevant interaction with the nonprofit organization were asked to participate.

Regarding the overall sample, $51 \%$ females and $49 \%$ males responded to the questionnaire and were roughly evenly distributed across all of the abovementioned groups. The average age was 22.1 years. Approximately $10 \%$ of the questionnaires were not answered in full, resulting in a missing value level of $1 \%$. Both the number of incomplete questionnaires and the number of missing values were almost equally distributed across the groups.

\section{Empirical study}

\subsection{Method}

The statistical analyses were performed with $\mathrm{R}$ 4.0.2 and additional R packages. All resampling techniques were performed with 6000 runs. Since 7-point scales were used, we treated the data as continuous. Furthermore, because the number of missing values was approximately evenly distributed among the groups, we did not eliminate incomplete questionnaires to preserve as much information as possible, and we treated missing values using the full information maximum likelihood estimation. Due to a significant number of nonnormal multivariate distribution (Mardia skewness $=5458.24$ and Mardia kurtosis $=70.25$ ) bootstrapped standard errors, $95 \%$ bias corrected (BC) confidence intervals and scaled test statistics were applied.

Since we identify theory-driven correlated ideal self-congruence and actual self-congruence, the number of covariances (15 per group) between latent variables of a confirmatory factor analysis (CFA) is identical to the number of regressions (13 per group) and covariances ( 2 per group) between the latent factors of the structural model. Therefore, a CFA would not provide any information that could not be obtained from a fully parameterized structural equations model (SEM). Hence, we used SEM in all subsequent analyses.

The scaled $\chi_{\mathrm{YB}}^{2}(786.13,522)<.001$ test result is significant for the configural multigroup model, indicating that the observed and model implied variance-covariance matrices differ considerably from each other. However, this is the case for almost all studies that do not meet extremely restrictive conditions, since the $\chi^{2}$ test and its scaled variants are known to be overly rigorous and sample size sensitive. We therefore utilized close fit statistics supplemented with incremental and descriptive fit indices. 


\subsection{Invariance tests and global fit}

As this study assumed that the relationships between the latent variables do not depend on the three considered nonprofit brands as long as their field of activity involves the mutual application of competencies with volunteers for the benefit of those in need (for instance, refugee assistance), multigroup models with the brand as the grouping variable were fit to examine whether configural (M0), metric (M1) and scalar (M2) invariance are present. We then searched for the most parsimonious model with which to perform the analysis by constraining the indicator residuals (M3), latent variable variances (M4), covariances between latent variables (M5), regressions within the structural model (M6), and latent variable means or intercepts (M7) across the groups.

Since the configural model does not perfectly reproduce the data, traditional and scaled $\chi^{2}$ difference tests are invalid. Furthermore, the comparison of fit index differences with rule-of-thumb thresholds is largely arbitrary and does not contribute significantly to confirmatory approaches. We therefore performed a series of permutation tests that enable a valid test of configural invariance, even if the model fits only approximately. Since permutation tests provide empirical sample distributions as a basis for calculating $p$-values, fit indices can also be applied for invariance tests without having to rely on rule-of-thumb cutoffs.

We utilized $\chi^{2}=916.396(p=.06)$, RMSEA $=.045(\mathrm{p}=.06)$, and CFI $=.962$ $(p=.05)$ to test M0. The obtained $\mathrm{p}$-values provide no evidence against configural equivalence across groups. M1 to M7 were tested using $\Delta \chi^{2}, \Delta$ RMSEA and $\Delta$ CFI, which consistently indicate that M6 is the most parsimonious model that can be considered equivalent and that M7 must be rejected (see Table 1).

On the basis of these results, we concluded that the nonprofit organizations' brands did not moderate the effects investigated and performed all further analyses with M6. The global fit indices show that the delineated model fits the data well $\left(\mathrm{RMSEA}=.04[.035, .046]\right.$, pclose $=1.00, \mathrm{CFI}=.96, \mathrm{NNFI}=.96, \mathrm{IFI}=.96, \chi_{\mathrm{YB}}^{2}$ ' $\mathrm{df}=937.05 / 666=1.41$, and $\mathrm{SRMR}=.07)$.

\subsection{Assessing reliability, convergent validity, and discriminant validity}

Due to the constraints of M6, standardized loadings and correlations between the latent variables are equal across all groups. Thus, the usual reliability and validity coefficients

Table 1 Invariance tests

\begin{tabular}{|c|c|c|c|c|c|c|}
\hline \multirow{2}{*}{$\begin{array}{l}\text { Model } \\
\text { M1 }(\Delta \mathrm{df}=30)\end{array}$} & \multicolumn{2}{|l|}{$\Delta \chi^{2}$} & \multicolumn{2}{|c|}{$\Delta$ RMSEA } & \multicolumn{2}{|l|}{$\Delta \mathrm{CFI}$} \\
\hline & 34.717 & $(p=.58)$ & -.002 & $(p=.70)$ & .000 & $(p=.66)$ \\
\hline $\mathrm{M} 2(\Delta \mathrm{df}=30)$ & 37.770 & $(p=.17)$ & .000 & $(p=.25)$ & -.001 & $(p=.17)$ \\
\hline $\mathrm{M} 3(\Delta \mathrm{df}=42)$ & 109.706 & $(p=.18)$ & -.001 & $(p=.34)$ & -.001 & $(p=.29)$ \\
\hline $\mathrm{M} 4(\Delta \mathrm{df}=12)$ & 25.630 & $(p=.20)$ & .000 & $(\mathrm{p}=.29)$ & -.001 & $(p=.24)$ \\
\hline M5 $(\Delta \mathrm{df}=4)$ & 3.094 & $(p=.82)$ & .000 & $(p=.80)$ & .001 & $(p=.85)$ \\
\hline $\operatorname{M6}(\Delta \mathrm{df}=26)$ & 33.299 & $(p=.67)$ & -.001 & $(p=.72)$ & .001 & $(p=.69)$ \\
\hline $\mathrm{M} 7(\Delta \mathrm{df}=12)$ & 51.060 & $(p=.00)$ & .002 & $(p=.00)$ & -.005 & $(\mathrm{p}=.00)$ \\
\hline
\end{tabular}


are cross-group identical and do not have to be reported separately for each group. The standardized loadings $(\beta)$ range from .69 to .88 (see Appendix Table 4). The factor reliabilities (FRs) range from .83 to .91 . The average variances extracted (AVEs) span from .56 to .78 and are all larger than the corresponding maximum shared variances (MSVs), which can be interpreted as the squared correlation of the factor consider with the factor with which it correlates most strongly (see Table 2 for details).

In sum, the analysis shows that all latent constructs have been reliably measured and that both convergent and discriminant validity are present.

\subsection{Hypothesis test}

For M6, the unstandardized regression coefficients $(\beta)$ and the variances of factors are identical across the groups. Accordingly, the standardized regression coefficients $(\beta)$ are also identical and allow a parsimonious cross-group estimation (see Table 3).

In line with hypotheses $\mathrm{H}_{1 \mathrm{a}}$ and $\mathrm{H}_{1 \mathrm{c}}$, perceived actual self-congruence and functional self-congruence have significant positive effects on volunteering intentions. Contrary to hypothesis $\mathrm{H}_{1 \mathrm{~b}}$, perceived ideal self-congruence does not affect volunteering intentions. Furthermore, neither self-congruence construct affects functional congruence. Finally, the analysis shows that both warmth and competence positively influence each of the three considered congruence constructs.

Appendix Table 5 shows the estimates of indirect and total effects, indicating that both warmth and competence have a significant total indirect effect and total effect on volunteering intentions. The total effect of actual self-congruence on volunteering intentions is significant, but mediation via functional congruence must nevertheless be rejected. Likewise, functional congruence does not mediate the effect of ideal self-congruence on volunteering intentions. In addition, a total effect of ideal self-congruence on volunteering intentions is not present. In sum and in line with hypothesis $\mathrm{H}_{2}$, the mediation analysis indicates that the effects of perceived warmth and perceived competence are mediated by the congruence constructs. However, a closer look at the specific indirect effects (see Appendix Table 5) reveals that only actual self-congruence and functional congruence act as mediators. Hence, contrary to hypothesis $\mathrm{H}_{2}$, ideal congruence does not mediate the effect of stereotypic image perceptions on volunteering intentions.

Table 2 Factor reliability, convergent and discriminant validity

\begin{tabular}{lllllllllll}
\hline Factor & SD & FR & AVE & MSV & PWA & PCO & SCI & SCR & FUC & INT \\
\hline PWA & 1.07 & .87 & .68 & .25 & .43 & & & & & \\
PCO & .92 & .83 & .62 & .29 & .47 & .33 & & & & \\
SCI & 1.07 & .91 & .78 & .51 & .37 & .36 & .27 & & & \\
SCR & .85 & .87 & .70 & .51 & .29 & .31 & .71 & .19 & & \\
FUC & .66 & .86 & .56 & .29 & .50 & .54 & .36 & .33 & .27 & \\
INT & 1.29 & .90 & .68 & .19 & .27 & .34 & .35 & .44 & .35 & .49 \\
\hline
\end{tabular}

$S D$ Standard deviation, FR Factor reliability, AVE Average variance extracted, $M S V$ Maximum shared variance, lower triangular matrix $=$ correlations, diagonal matrix $=$ AVE minus MSV, PWA Perceived warmth, PCO Perceived competence, SCI Ideal self-congruence, SCR Actual self-congruence, FUC Functional congruence, INT Volunteering intention 
Table 3 Direct effects

\begin{tabular}{llllllll}
\hline Cause $\rightarrow$ Effect & B & Lower & Upper & se & z & & $\beta$ \\
\hline $\mathrm{PWA} \rightarrow$ SCI & .29 & .16 & .41 & .06 & 4.64 & $* * *$ & .26 \\
$\mathrm{PWA} \rightarrow \mathrm{SCR}$ & .15 & .05 & .26 & .05 & 2.88 & $* *$ & .18 \\
$\mathrm{PWA} \rightarrow \mathrm{FUC}$ & .22 & .14 & .31 & .04 & 5.25 & $* * *$ & .28 \\
$\mathrm{PWA} \rightarrow \mathrm{INT}$ & .05 & -.11 & .21 & .08 & .62 & $\mathrm{~ns}$ & .04 \\
$\mathrm{PCO} \rightarrow \mathrm{SCI}$ & .30 & .16 & .44 & .07 & 4.33 & $* * *$ & .23 \\
$\mathrm{PCO} \rightarrow \mathrm{SCR}$ & .23 & .12 & .34 & .06 & 4.07 & $* * *$ & .23 \\
$\mathrm{PCO} \rightarrow \mathrm{FUC}$ & .32 & .21 & .43 & .05 & 5.99 & $* * *$ & .35 \\
$\mathrm{PCO} \rightarrow \mathrm{INT}$ & .23 & .02 & .45 & .11 & 2.16 & $*$ & .14 \\
$\mathrm{SCI} \rightarrow \mathrm{FUC}$ & .04 & -.05 & .13 & .05 & .88 & $\mathrm{~ns}$ & .06 \\
$\mathrm{SCI} \rightarrow \mathrm{INT}$ & .00 & -.19 & .17 & .09 & .00 & $\mathrm{~ns}$ & .00 \\
$\mathrm{SCR} \rightarrow \mathrm{FUC}$ & .09 & -.03 & .21 & .06 & 1.48 & $\mathrm{~ns}$ & .10 \\
$\mathrm{SCR} \rightarrow \mathrm{INT}$ & .55 & .34 & .79 & .11 & 4.81 & $* * *$ & .33 \\
$\mathrm{FUC} \rightarrow \mathrm{INT}$ & .26 & .02 & .47 & .11 & 2.25 & $*$ & .14 \\
\hline
\end{tabular}

$B$ Unstandardized regression, Lower and Upper $=$ limits of $95 \% \mathrm{BC}$ confidence interval, SE Standard error, $Z$ Z-score, significance: ${ }^{* * *}$ $0.1 \%,{ }^{* *} 1 \%,{ }^{*} 5 \%,{ }^{\mathrm{ns}}$ nonsignificant, $\beta$ Standardized regression, $P W A$ Perceived warmth, $P C O$ Perceived competence, $S C I$ Ideal self-congruence, SCR Actual self-congruence, FUC Functional congruence, INT Volunteering intention

\section{Discussion of study results}

\subsection{Direct effects of the congruence constructs (hypotheses $\mathrm{H}_{1 \mathrm{a}}-\mathrm{H}_{1 \mathrm{c}}$ )}

Confirming hypotheses $\mathrm{H}_{1 \mathrm{a}}$ and $\mathrm{H}_{1 \mathrm{c}}$, actual self-congruence and functional congruence have significant positive effects on volunteering intentions. In line with self-congruence research (Liberman et al., 1999), with regard to the effect of actual self-congruence, potential student volunteers apparently regard volunteering as a means to satisfy self-consistency motives. Thus, volunteering seems to be an activity that enables students to confirm their self-image and to be at peace with themselves. Interestingly, Zogaj et al. (2020) show that actual self-congruence only has an effect on the willingness to donate in highly involved individuals. Considering this finding, the positive effect of actual self-congruence found in the present study can probably be explained by the fact that volunteer commitment requires a high level of personal involvement. As Batra and Ahtola (1991) highlight, the effect of functional congruency is based on utilitarian consumption motives. Since volunteering cannot satisfy consumption needs, other utilitarian motives must be behind the proven effect. Research on other domains of prosocial behavior (Klein et al., 2004) has shown that the possibility of making a difference motivates selfless behavior. In line with this idea, functional congruency, which reflects nonprofit organizations' efficiency and effectiveness, may have a positive effect on volunteering intentions because students only want to engage with 'highperformance' organizations that achieve positive outcomes in society.

Contrary to hypothesis $\mathrm{H}_{1 \mathrm{~b}}$, ideal self-congruency has no effect on volunteering intentions. Even if this result does not confirm $\mathrm{H}_{1 \mathrm{~b}}$, it aligns with previous research showing that involvement decreases the effect of ideal self-congruence (see, e.g., 
Malär et al., 2011; Zogaj et al., 2020) if one considers that volunteering is a highinvolvement activity. Furthermore, a few previous self-congruence studies have also failed to demonstrate an effect of ideal self-congruence (e.g., Fritz et al., 2017). Apparently, volunteering is not seen as a way to bring one's self-image closer to an ideal image. This can be explained by the notion that university students might already find themselves more closely emulating to a desired societal or peer-groupspecific ideal than other persons due to their higher educational achievements. This notion is supported by earlier psychological research (Denmark \& Guttentag, 1967) showing that the discrepancy between the actual and ideal self-image is lower (higher) among women (not) seeking a university education. Furthermore, this notion is also in line with Malär et al.'s (2011) research, which identifies self-confidence as a moderating variable. More precisely, the authors show that ideal self-congruence can have a positive effect on behavioral variables in individuals with low self-confidence. Hence, it can be assumed that the students in the present sample had higher average self-confidence due to their qualifications and status within their age group. Accordingly, the discrepancy between the self-concept and the ideal self-image of the examined university students should have been comparatively small. If this is the case, the effect of ideal self-congruence on volunteering intentions is not particularly pronounced in the present sample due to the low salience of the self-enhancement motive. This line of argumentation is also reflected in Zogaj et al.'s (2020) results for a broad population cross-section. In this study, which examines a sample with a lower proportion of students and individuals with a university degree, ideal self-congruence is found to have a positive effect on prosocial behavior (i.e., donation behavior).

\subsection{Mediating effects of the congruency constructs (hypothesis $\mathrm{H}_{2}$ )}

The finding that perceived warmth and competence have significant effects on actual and ideal self-congruence is in line with this paper's conceptual considerations. Because individuals tend to evaluate themselves more positively than the average person (that is, the abovementioned self-positivity bias; see Zhang et al., 2013), actual self-congruence must increase as the perceived competence and warmth of a nonprofit organization rise. Moreover, it is logically obvious that the perceived competence of a volunteer organization has a positive effect on functional congruence. Perceived warmth also has a significant positive effect on functional congruence. Initially, for a typical consumption context, this is surprising because functional congruence relates to utilitarian product attributes (Choi \& Reid, 2016). However, since the mission of the considered nonprofit organizations is to alleviate human suffering, not only purely utilitarian and economic criteria seem to play roles in the formation of functional congruence.

As a contribution to self-congruence research in general and in line with hypothesis $\mathrm{H}_{2}$, this study reveals a mediating effect of actual self-congruence and functional congruence on the relationship between stereotypic image perceptions and volunteering intentions. Hence, stereotypic image perceptions of nonprofit organizations represent a manifestation of the congruence-formation process, which is an important insight since empirical findings on the antecedents of self-congruence are rather 
scarce. In one of the few studies with this focus, Roy and Rabbanee (2015) show that the need for uniqueness and status affects the perceived self-congruency of consumers of luxury products. Accordingly, this study adds perceived warmth and perceived competence as two new antecedents to the self-congruence literature.

\section{Conclusions}

The present study shows that stereotypic image perceptions of nonprofit organizations (i.e., warmth and competence) and congruence constructs affect the volunteering intentions of university students. First, ideal self-congruence, in contrast to the significant effect of actual self-congruence, has no effect on intentions to volunteer. Second, functional congruence was found to have a direct and positive effect on the willingness to volunteer. Third, this study reveals that perceived competence and perceived warmth are antecedents of the considered congruence constructs. Finally, the mediation analysis indicates that actual and functional congruence convey the effects of stereotypic image perceptions on the volunteering intentions of university students.

Considering the empirical findings of this study, first, nonprofit organizations should focus on potential volunteers' actual self-congruence. Therefore, first, nonprofit managers should assess the average actual self-congruence of relevant target groups, which could be carried out as Randle and Dolnicar (2011) do in their study. Based on the insights generated from these analyses, volunteer organizations could develop tailored communication campaigns that increase the fit between the actual self-image of the recipients and a nonprofit organization's brand image. Unilever's Dove campaigns serve as an example of how commercial companies' communication strategies can increase actual self-congruence (see Japutra et al., 2019). Nonprofit organizations could use this type of noncelebrity endorsement communication strategy to enhance perceptions of actual self-congruity. The accordant communication stimuli could depict 'students like you and me' who work as volunteers and to whom recipients can easily relate and perceive as warm and competent. Second, nonprofits should use the motivating effect of functional congruence proven in this study. Since mission fulfillment is very important for all nonprofit organizations (Herman \& Renz, 1998), it is evident that all such organizations should strive for effectiveness. However, improving effectiveness is not an easily and quickly achievable task. For this very reason, however, high-performing nonprofit organizations should regularly communicate their successes to achieve high levels of perceived competence and in turn high degrees of perceived functional congruence among potential volunteers. Third, voluntary organizations should aim to improve their image with regard to their perceived warmth. Interestingly, Ren et al. (2018) show that handwritten communication results in perceived warmth through the arousal of felt personal closeness. Nonprofit organizations could use this effect when designing printed or other visual volunteering appeals. Huang and Liu's (2020) research offers similar results and shows that a combination of handwritten typeface and warmth-focused message framing is particularly effective at evoking prosocial action tendencies. Furthermore, based on Cuddy et al. (2008), nonprofit organizations could use persons from noncompetitive 
social groups (for instance, children of similar sociocultural backgrounds) in their communication campaigns to strengthen their perceived warmth.

The results of this study must be interpreted in light of its limitations. First, the study uses a student sample from Germany, raising questions surrounding whether and to what extent the presented results can be transferred to, for example, the rest of the German population or students in other countries. Second, it can be assumed that university students have heterogeneous motives to volunteer. This heterogeneity was not explicitly taken into account in the present study. However, this study was not able to demonstrate pronounced gender effects in an additional multigroup analysis not reported in this paper. Third, it must be noted that this paper presents a survey study, and therefore, no strict causality statements can be made. Accordingly, no clear conclusions can be drawn about the causal order of the observed effects. For instance, Zogaj et al. (2021) demonstrate a mediating effect of influencers' perceived competence on the relationship between ideal self-congruence and intentions to purchase electronic products. However, Zogaj et al.'s (2021) competence construct refers to the informational content of video clips posted by influencers and therefore cannot be compared to the perceptions of nonprofit organizations' competence considered in the present study. Finally, it must be recognized that behavioral intentions rather than actual behavior were measured in the present study.

This study provides several avenues for future research. First, considering the abovementioned study limitations, the delineated model of volunteering behavior could be tested in other countries and populations. Among other benefits, this approach would make it possible to determine whether ideal self-congruence in other population groups has an effect after all. Moreover, future research could correlate self-congruity with actual volunteering behavior in longitudinal studies. Second, to increase internal validity, experimental studies could be conducted. Here, perceived congruence could be manipulated by considering different endorsers of voluntary work (that is, endorsers whose image closely or does not closely reflect ideal or actual self-concepts). Cruce and Moore (2007) show that age, gender, and other demographic factors explain first-year students' willingness to volunteer. Third, future studies could thus investigate whether self-congruence can explain the psychological mechanisms shaping the effects of these volunteers' sociodemographic characteristics. Brewis and Holdsworth (2011) show through their study that university support for engaged students is important in achieving positive volunteering outcomes. Fourth, and building on this focus, future research could examine whether volunteer management influences volunteers' perceptions of self-congruence and how these perceptions affect volunteering outcomes over time. Fifth, other constructs could be added to our model. For instance, based on the work of MacKay et al. (2016), personal and group norms could be considered further antecedents of self-congruence. Authors such as McGloin and Georgeou (2015) also identify a 'dark side' to volunteering. It is unfavorable when a commitment arises from volunteers' sense of superiority over their beneficiaries. Accordingly, student volunteer programs should be designed such (e.g., through seminars and coaching) that no power imbalance arises between those helping and those in need of help. Congruence between the self-image of helpers and their perceptions of individuals in need of help can be used here as an indicator of a possible existing power imbalance. 


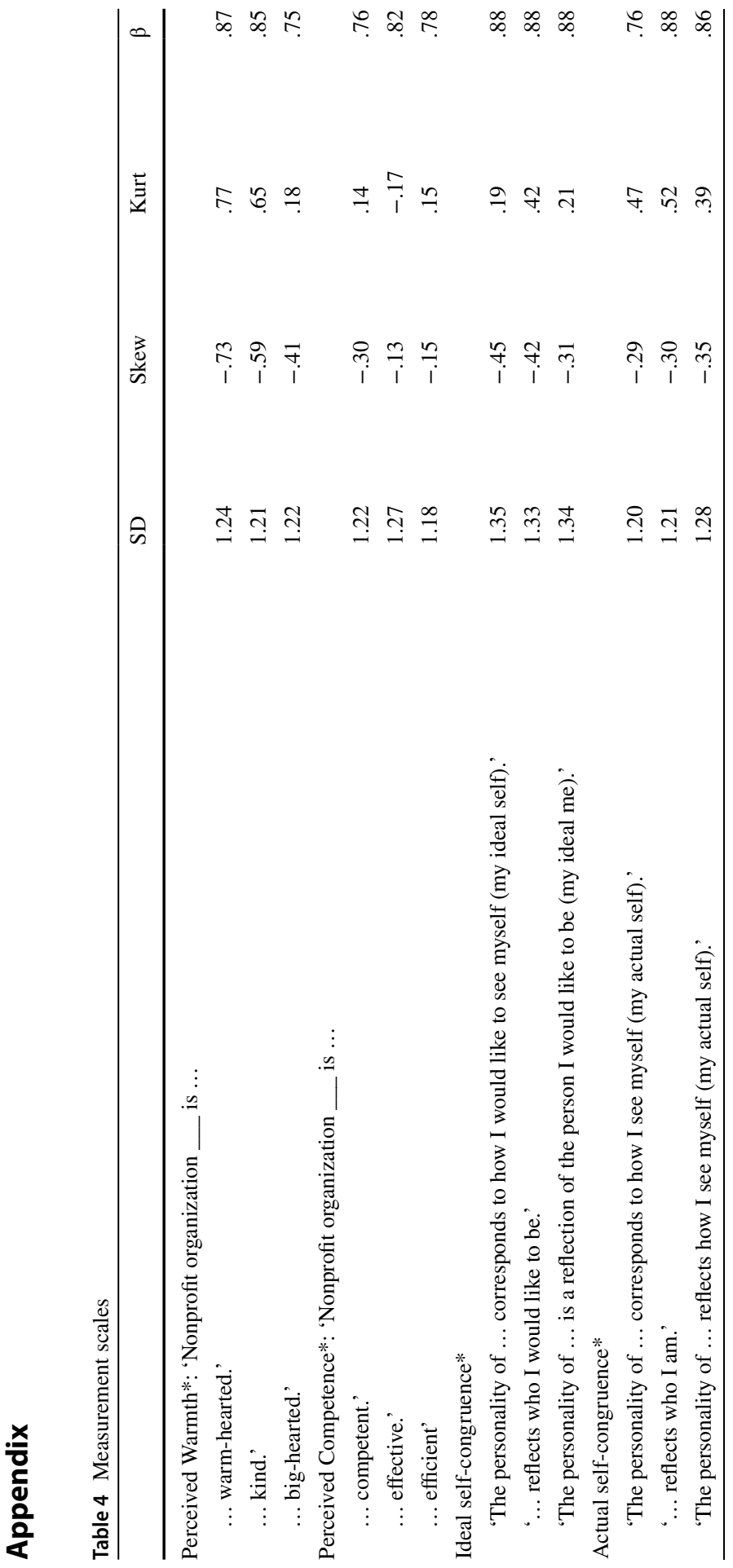




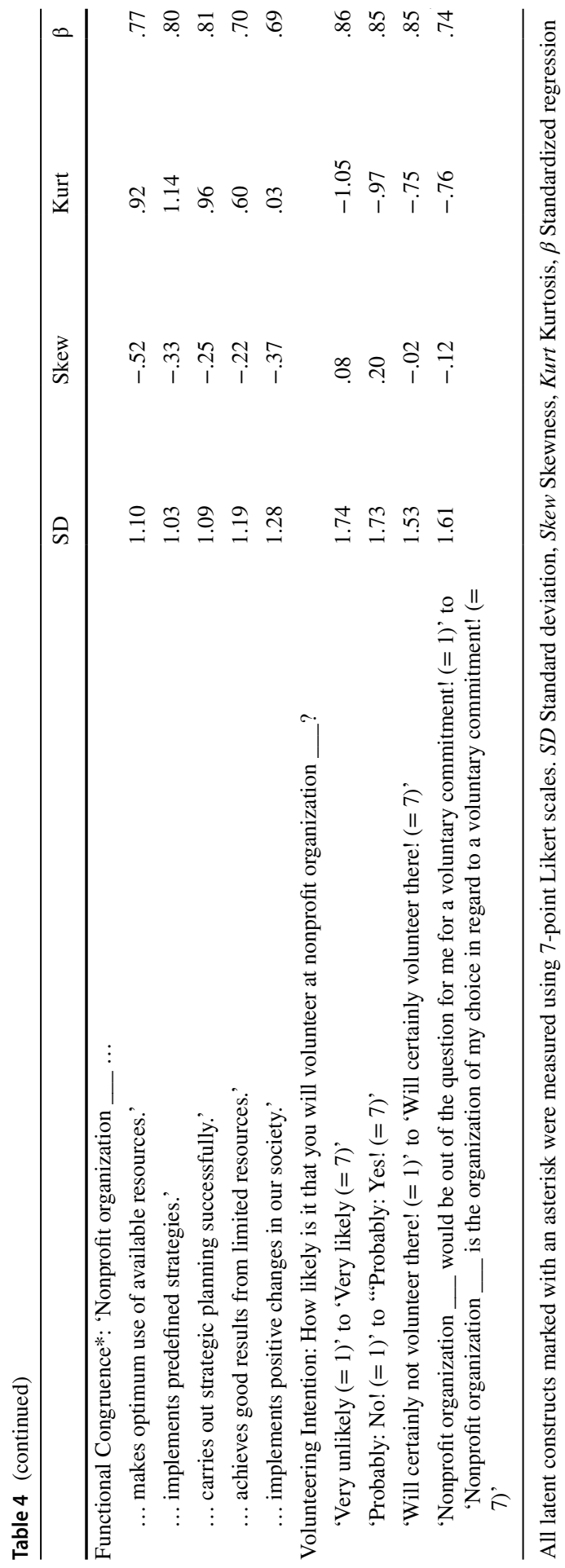


Table 5 Indirect and total effects

\begin{tabular}{|c|c|c|c|c|c|c|c|}
\hline Effect & B & Lower & Upper & se & $\mathrm{z}$ & & $\beta$ \\
\hline $\mathrm{PWA} \rightarrow \mathrm{SCI} \rightarrow \mathrm{FUC}$ & .01 & -.01 & .04 & .01 & .86 & ns & .01 \\
\hline $\mathrm{PWA} \rightarrow \mathrm{SCR} \rightarrow \mathrm{FUC}$ & .01 & .00 & .04 & .01 & 1.22 & ns & .02 \\
\hline $\mathrm{PWA} \rightarrow \mathrm{FUC}$ (total indirect) & .02 & .00 & .05 & .01 & 2.00 & $*$ & .03 \\
\hline PWA $\rightarrow$ FUC (total) & .25 & .17 & .33 & .04 & 5.85 & $* * *$ & .32 \\
\hline $\mathrm{PWA} \rightarrow \mathrm{SCI} \rightarrow \mathrm{INT}$ & .00 & -.05 & .05 & .03 & .00 & ns & .00 \\
\hline $\mathrm{PWA} \rightarrow \mathrm{SCR} \rightarrow \mathrm{INT}$ & .08 & .03 & .16 & .03 & 2.48 & $*$ & .06 \\
\hline $\mathrm{PWA} \rightarrow \mathrm{SCI} \rightarrow \mathrm{FUC} \rightarrow \mathrm{INT}$ & .00 & .00 & .01 & .00 & .77 & ns & .00 \\
\hline $\mathrm{PWA} \rightarrow \mathrm{SCR} \rightarrow \mathrm{FUC} \rightarrow \mathrm{INT}$ & .00 & .00 & .02 & .00 & .97 & ns & .00 \\
\hline $\mathrm{PWA} \rightarrow \mathrm{FUC} \rightarrow \mathrm{INT}$ & .06 & .01 & .12 & .03 & 1.88 & $\mathrm{~ns}$ & .04 \\
\hline $\mathrm{PWA} \rightarrow \mathrm{INT}$ (total indirect) & .15 & .06 & .25 & .05 & 2.93 & $* *$ & .10 \\
\hline $\mathrm{PWA} \rightarrow \mathrm{INT}$ (total) & .20 & .04 & .35 & .08 & 2.52 & $*$ & .14 \\
\hline $\mathrm{PCO} \rightarrow \mathrm{SCI} \rightarrow \mathrm{FUC}$ & .01 & -.01 & .04 & .01 & .83 & ns & .01 \\
\hline $\mathrm{PCO} \rightarrow \mathrm{SCR} \rightarrow \mathrm{FUC}$ & .02 & .00 & .05 & .01 & 1.43 & ns & .02 \\
\hline $\mathrm{PCO} \rightarrow \mathrm{FUC}$ (total indirect) & .03 & .01 & .06 & .01 & 2.42 & $*$ & .04 \\
\hline $\mathrm{PCO} \rightarrow \mathrm{FUC}($ total) & .36 & .25 & .46 & .05 & 6.80 & $* * *$ & .39 \\
\hline $\mathrm{PCO} \rightarrow \mathrm{SCI} \rightarrow \mathrm{INT}$ & .00 & -.06 & .05 & .03 & .00 & ns & .00 \\
\hline $\mathrm{PCO} \rightarrow \mathrm{SCR} \rightarrow \mathrm{INT}$ & .12 & .06 & .23 & .04 & 3.02 & $* *$ & .08 \\
\hline $\mathrm{PCO} \rightarrow \mathrm{SCI} \rightarrow \mathrm{FUC} \rightarrow \mathrm{INT}$ & .00 & .00 & .01 & .00 & .75 & $\mathrm{~ns}$ & .00 \\
\hline $\mathrm{PCO} \rightarrow \mathrm{SCR} \rightarrow \mathrm{FUC} \rightarrow \mathrm{INT}$ & .01 & .00 & .02 & .00 & 1.11 & $\mathrm{~ns}$ & .00 \\
\hline $\mathrm{PCO} \rightarrow \mathrm{FUC} \rightarrow \mathrm{INT}$ & .08 & .01 & .17 & .04 & 2.05 & $*$ & .05 \\
\hline $\mathrm{PCO} \rightarrow \mathrm{INT}$ (total indirect) & .22 & .10 & .34 & .06 & 3.58 & $* * *$ & .13 \\
\hline $\mathrm{PCO} \rightarrow \mathrm{INT}($ total $)$ & .45 & .25 & .64 & .10 & 4.54 & $* * *$ & .28 \\
\hline $\mathrm{SCI} \rightarrow \mathrm{FUC} \rightarrow \mathrm{INT}$ & .01 & -.01 & .04 & .01 & .80 & $\mathrm{~ns}$ & .01 \\
\hline $\mathrm{SCI} \rightarrow \mathrm{INT}($ total $)$ & .01 & -.18 & .18 & .09 & .11 & ns & .01 \\
\hline $\mathrm{SCR} \rightarrow \mathrm{FUC} \rightarrow \mathrm{INT}$ & .02 & .00 & .08 & .02 & 1.15 & ns & .01 \\
\hline $\mathrm{SCR} \rightarrow \mathrm{INT}$ (total) & .57 & .36 & .82 & .11 & 4.98 & $* * *$ & .35 \\
\hline
\end{tabular}

$B$ Unstandardized regression, Lower and Upper $=$ limits of $95 \%$ BC confidence interval, SE Standard error, Z Z-score, significance: ${ }^{* * *} 0.1 \%,{ }^{* *} 1 \%,{ }^{*} 5 \%,{ }^{\text {ns }}$ nonsignificant, $\beta$ Standardized regression, $P W A$ Perceived warmth, $P C O$ Perceived competence, SCI Ideal self-congruence, SCR Actual self-congruence, FUC Functional congruence, INT Volunteering intention

Funding Open Access funding enabled and organized by Projekt DEAL. The author(s) received no financial support for the research, authorship, and/or publication of this article.

Data availability Available from the corresponding author.

Code availability Available from the corresponding author.

\section{Declarations}

Conflicts of interest/competing interests The author(s) declared no potential conflicts of interest with respect to the research, authorship, and/or publication of this article. 
Open Access This article is licensed under a Creative Commons Attribution 4.0 International License, which permits use, sharing, adaptation, distribution and reproduction in any medium or format, as long as you give appropriate credit to the original author(s) and the source, provide a link to the Creative Commons licence, and indicate if changes were made. The images or other third party material in this article are included in the article's Creative Commons licence, unless indicated otherwise in a credit line to the material. If material is not included in the article's Creative Commons licence and your intended use is not permitted by statutory regulation or exceeds the permitted use, you will need to obtain permission directly from the copyright holder. To view a copy of this licence, visit http://creativecommons.org/licen ses/by/4.0/.

\section{References}

Aaker, J., Vohs, K. D., \& Mogilner, C. (2010). Nonprofits are seen as warm and for-profits as competent: Firm stereotypes matter. Journal of Consumer Research, 37(2), 224-237.

Ackermann, K. (2019). Predisposed to volunteer? Personality traits and different forms of volunteering. Nonprofit and Voluntary Sector Quarterly, 48(6), 1119-1142.

Ahn, T., Ekinci, Y., \& Li, G. (2013). Self-congruence, functional congruence, and destination choice. Journal of Business Research, 66(6), 719-723.

Andreoni, J., Gale, W. G., Scholz, J. K., \& Straub, J. (1996). Charitable contributions of time and money. University of Wisconsin-Madison Working Paper.

Aydinli, A., Bender, M., Chasiotis, A., van de Vijver, F. J., Cemalcilar, Z., Chong, A., \& Yue, X. (2016). A cross-cultural study of explicit and implicit motivation for long-term volunteering. Nonprofit and Voluntary Sector Quarterly, 45(2), 375-396.

Baghi, I., \& Gabrielli, V. (2013). Co-branded cause-related marketing campaigns: The importance of linking two strong brands. International Review on Public and Nonprofit Marketing, 10(1), 13-29.

Bahat, E. (2020). Person-organization fit and commitment to volunteer organizations. Voluntas. https://doi.org/10.1007/s11266-020-00212-x.

Batra, R., \& Ahtola, O. T. (1991). Measuring the hedonic and utilitarian sources of consumer attitudes. Marketing Letters, 2(2), 159-170.

Beerli, A., Díaz, G., \& Martín, J. D. (2004). The behavioural consequences of self-congruency in volunteers. International Journal of Nonprofit and Voluntary Sector Marketing, 9(1), 28-48.

Bennett, R. (2009). Factors influencing donation switching behaviour among charity supporters: An empirical investigation. Journal of Customer Behaviour, 8(4), 329-345.

Bodenhausen, G. V. (1990). Stereotypes as judgmental heuristics: Evidence of circadian variations in discrimination. Psychological Science, 1(5), 319-322.

Boenigk, S., \& Becker, A. (2016). Toward the importance of nonprofit brand equity: Results from a study of German nonprofit organizations. Nonprofit Management \& Leadership, 27(2), 181-198.

Boseovski, J. J. (2010). Evidence for "rose-colored glasses": An examination of the positivity bias in young children's personality judgments. Child Development Perspectives, 4(3), 212-218.

Brewis, G., \& Holdsworth, C. (2011). University support for student volunteering in England: Historical development and contemporary value. Journal of Academic Ethics, 9(2), 165-176.

Burns, D. J., Reid, J. S., Toncar, M., Fawcett, J., \& Anderson, C. (2006). Motivations to volunteer: The role of altruism. International Review on Public and Nonprofit Marketing, 3(2), 79-91.

Caprariello, P. A., Cuddy, A. J., \& Fiske, S. T. (2009). Social structure shapes cultural stereotypes and emotions: A causal test of the stereotype content model. Group Processes \& Intergroup Relations, 12(2), 147-155.

Chatwin, J., \& Ackers, L. (2016). Volunteering and overseas placements in the NHS: A survey of current activity. BMJ Open, 6(10), e012160-e012160.

Choi, H., \& Reid, L. N. (2016). Congruity effects and moderating influences in nutrient-claimed food advertising. Journal of Business Research, 69(9), 3430-3438.

Cicognani, E., Mazzoni, D., Albanesi, C., \& Zani, B. (2015). Sense of community and empowerment among young people: Understanding pathways from civic participation to social well-being. Voluntas: International Journal of Voluntary and Nonprofit Organizations, 26(1), 24-44. 
Claiborne, C. B., \& Sirgy, M. J. (2015). Self-image congruence as a model of consumer attitude formation and behavior: A conceptual review and guide for future research. In Proceedings of the 1990 Academy of Marketing Science (AMS) Annual Conference (pp. 1-7). Springer.

Clary, E. G., Snyder, M., \& Ridge, R. (1992). Volunteers' motivations: A functional strategy for the recruitment, placement, and retention of volunteers. Nonprofit Management \& Leadership, 2(4), $333-350$.

Cnaan, R. A., Handy, F., \& Wadsworth, M. (1996). Defining who is a volunteer: Conceptual and empirical considerations. Nonprofit and Voluntary Sector Quarterly, 25(3), 364-383.

Crocetti, E., Jahromi, P., \& Meeus, W. (2012). Identity and civic engagement in adolescence. Journal of Adolescence, 35(3), 521-532.

Cruce, T. M., \& Moore, J. V. (2007). First-year students' plans to volunteer: An examination of the predictors of community service participation. Basic and Applied Psychology, 48(6), 655-673.

Cuddy, A. J., Fiske, S. T., \& Glick, P. (2008). Warmth and competence as universal dimensions of social perception: The stereotype content model and the BIAS map. Advances in Experimental Social Psychology, 40, 61-149.

Davis, R., \& Lang, B. (2013). Does game self-congruity increase usage and purchase? Young Consumers: Insight and Ideas for Responsible Marketers, 14(1), 52-66.

Denmark, F. L., \& Guttentag, M. (1967). Dissonance in the self-concepts and educational concepts of college-and non-college-oriented women. Journal of Counseling Psychology, 14(2), 113-115.

Dickinson, S., \& Barker, A. (2007). Evaluations of branding alliances between non-profit and commercial brand partners: The transfer of affect. International Journal of Nonprofit and Voluntary Sector Marketing, 12(1), 75-89.

Drevs, F., Tscheulin, D. K., \& Lindenmeier, J. (2014). Do patient perceptions vary with ownership status? A study of nonprofit, for-profit, and public hospital patients. Nonprofit and Voluntary Sector Quarterly, 43(1), 164-184.

Eliasoph, N. (2013). The politics of volunteering. Wiley.

Emens, S., White, D. W., Klein, T. A., Edwards, Y. D., Mann, S. R., \& Flaschner, A. B. (2014). Self-congruity and the MOA framework: An integrated approach to understanding social cause community volunteer participation. Journal of Marketing Development \& Competitiveness, 8(3), 70-83.

Fiske, S. T. (2015). Intergroup biases: A focus on stereotype content. Current Opinion in Behavioral Sciences, 3, 45-50.

Fiske, S. T., Cuddy, A. J., Glick, P., \& Xu, J. (2002). A model of (often mixed) stereotype content: Competence and warmth respectively follow from perceived status and competition. Journal of Personality and Social Psychology, 82(6), 878.

Francis, J. E. (2011). The functions and norms that drive university student volunteering. International Journal of Nonprofit and Voluntary Sector Marketing, 16(1), 1-12.

Fritz, K., Schoenmüller, V., \& Bruhn, M. (2017). Authenticity in branding-exploring antecedents and consequences of brand authenticity. European Journal of Marketing, 51(2), 324-348.

Gazley, B., Littlepage, L., \& Bennett, T. A. (2012). What about the host agency? Nonprofit perspectives on community-based student learning and volunteering. Nonprofit and Voluntary Sector Quarterly, 41(6), 1029-1050.

Gilmore, G. W. (1919). Animism: Or, thought currents of primitive peoples 1. Library of Alexandria.

Hackl, F., Halla, M., \& Pruckner, G. J. (2012). Volunteering and the state. Public Choice, 151(3-4), 465-495.

Handy, F., \& Mook, L. (2011). Volunteering and volunteers: Benefit-cost analyses. Research on Social Work Practice, 21(4), 412-420.

Haski-Leventhal, D., Paull, M., Young, S., MacCallum, J., Holmes, K., Omari, M., et al. (2020). The multidimensional benefits of university student volunteering: Psychological contract, expectations, and outcomes. Nonprofit and Voluntary Sector Quarterly, 49(1), 113-133.

Herman, R. D., \& Renz, D. O. (1998). Nonprofit organizational effectiveness: Contrasts between especially effective and less effective organizations. Nonprofit Management \& Leadership, 9(1), 23-38.

Hong, J. W., \& Zinkhan, G. M. (1995). Self-concept and advertising effectiveness: The influence of congruency, conspicuousness, and response mode. Psychology \& Marketing, 12(1), 53-77.

Huang, H., \& Liu, S. Q. (2020). Donate to help combat COVID-19! How typeface affects the effectiveness of CSR marketing? International Journal of Contemporary Hospitality Management, 32(10), 3315-333. 
Hung, K., \& Petrick, J. F. (2012). Testing the effects of congruity, travel constraints, and self-efficacy on travel intentions: An alternative decision-making model. Tourism Management, 33(4), 855-867.

Hustinx, L., Cnaan, R. A., \& Handy, F. (2010a). Navigating theories of volunteering: A hybrid map for a complex phenomenon. Journal for the Theory of Social Behaviour, 40(4), 410-434.

Hustinx, L., Handy, F., Cnaan, R. A., Brudney, J. L., Pessi, A. B., \& Yamauchi, N. (2010b). Social and cultural origins of motivations to volunteer: A comparison of university students in six countries. International Sociology, 25(3), 349-382.

Janoski, T., Musick, M., \& Wilson, J. (1998). Being volunteered? The impact of social participation and pro-social attitudes on volunteering. Sociological Forum, 23(3), 495-519.

Japutra, A., Ekinci, Y., \& Simkin, L. (2019). Self-congruence, brand attachment and compulsive buying. Journal of Business Research, 99, 456-463.

Jenner, J. R. (1982). Participation, leadership, and the role of volunteerism among selected women volunteers. Journal of Voluntary Action Research, 11(4), 27-38.

Johar, J. S., \& Sirgy, M. J. (1991). Value-expressive versus utilitarian advertising appeals: When and why to use which appeal. Journal of Advertising, 20(3), 23-33.

Kirk, G., \& Beth Nolan, S. (2010). Nonprofit mission statement focus and financial performance. Nonprofit Management \& Leadership, 20(4), 473-490.

Klein, J. G., Smith, N. C., \& John, A. (2004). Why we boycott: Consumer motivations for boycott participation. Journal of Marketing, 68(3), 92-109.

Kressmann, F., Sirgy, M. J., Herrmann, A., Huber, F., Huber, S., \& Lee, D. J. (2006). Direct and indirect effects of self-image congruence on brand loyalty. Journal of Business Research, 59(9), 955-964.

Kuo, A., \& Rice, D. H. (2015). The impact of perceptual congruence on the effectiveness of cause-related marketing campaigns. Journal of Consumer Psychology, 25(1), 78-88.

Lee, K. (2010). The green purchase behavior of Hong Kong young consumers: The role of peer influence, local environmental involvement, and concrete environmental knowledge. Journal of International Consumer Marketing, 23(1), 21-44.

Liberman, N., Idson, L. C., Camacho, C. J., \& Higgins, E. T. (1999). Promotion and prevention choices between stability and change. Journal of Personality and Social Psychology, 77(6), 1135-1145.

Lilley, A., \& Slonim, R. (2014). The price of warm glow. Journal of Public Economics, 114, 58-74.

Lindenmeier, J. (2014). Emotions in prosocial decision making: An editorial essay. Journal of Nonprofit \& Public Sector Marketing, 26(4), 281-289.

Lu, J., \& Xu, Y. (2015). Chinese young consumers' brand loyalty toward sportswear products: A perspective of self-congruity. The Journal of Product and Brand Management, 24(4), 365-376.

Mackay, S. A., White, K. M., \& Obst, P. L. (2016). Sign and share: What influences our participation in online microvolunteering. Cyberpsychology, Behavior and Social Networking, 19(4), 257-263.

Malär, L., Krohmer, H., Hoyer, W. D., \& Nyffenegger, B. (2011). Emotional brand attachment and brand personality: The relative importance of the actual and the ideal self. Journal of Marketing, 75(4), 35-52.

McGloin C, \& Georgeou N. (2015). Looks good on your CV: The sociology of voluntourism recruitment in higher education. Journal of Sociology, 52(2):403-417.

Menchik, P. L., \& Weisbrod, B. A. (1987). Volunteer labor supply. Journal of Public Economics, 32(2), $159-183$.

Musick, M. A., \& Wilson, J. (2007). Volunteers: A social profile. Indiana University Press.

OECD (n.d.). Women are catching up to men in volunteering, and they engage in more altruistic voluntary activities. https://www.oecd.org/gender/data/women-are-catching-up-to-men-in-volunteeringand-they-engage-in-more-altruistic-voluntary-activities.htm. Oct 5, 2020.

Ottoni-Wilhelm, M. (2017). Altruism and Egoism/Warm Glow in Economics and Psychology: Building a Bridge Between Different Experimental Approaches. In M. Costa-Font \& M. Macis (Eds.), Social economics: Current and emerging avenues. MIT Press.

Pan, T. J. (2012). Motivations of volunteer overseas and what have we learned-the experience of Taiwanese students. Tourism Management, 33(6), 1493-1501.

Randle, M., \& Dolnicar, S. (2011). Self-congruity and volunteering: A multi-organisation comparison. European Journal of Marketing, 45(5), 739-758.

Ren, X., Xia, L., \& Du, J. (2018). Delivering warmth by hand: Customer responses to different formats of written communication. Journal of Services Marketing, 32(2), 223-234.

Rosenberg, M. (1979). Conceiving the self. Basic Books.

Roy, R., \& Rabbanee, F. K. (2015). Antecedents and consequences of self-congruity. European Journal of Marketing, 49(3-4), 444-466. 
Shields, P. O. (2009). Young adult volunteers: Recruitment appeals and other marketing considerations. Journal of Nonprofit \& Public Sector Marketing, 21(2), 139-159.

Sirgy, M. J. (1982). Self-concept in consumer behavior: A critical review. Journal of Consumer Research, 9(3), 287-300.

Sirgy, M. J. (1986). Self-congruity: Toward a theory of personality and cybernetics. Praeger Publishers/ Greenwood Publishing Group.

Sirgy, M. J., Grewal, D., Mangleburg, T. F., Park, J. O., Chon, K. S., Claiborne, C. B., ... \& Berkman, H. (1997). Assessing the predictive validity of two methods of measuring self-image congruence. Journal of the Academy of Marketing Science, 25(3), 229-241.

Sirgy, M. J., Johar, J. S., Samli, A. C., \& Claiborne, C. B. (1991). Self-congruity versus functional congruity: Predictors of consumer behavior. Journal of the Academy of Marketing Science, 19(4), 363-375.

Smith, D. H. (1994). Determinants of voluntary association participation and volunteering: A literature review. Nonprofit and Voluntary Sector Quarterly, 23(3), 243-263.

Smith, K., Holmes, K., Haski-Leventhal, D., Cnaan, R. A., Handy, F., \& Brudney, J. L. (2010). Motivations and benefits of student volunteering: Comparing regular, occasional, and non-volunteers in five countries. Canadian Journal of Nonprofit and Social Economy Research, 1(1), 65-81.

Stephenson, A. L., \& Bell, N. (2014). Motivation for alumni donations: A social identity perspective on the role of branding in higher education. International Journal of Nonprofit and Voluntary Sector Marketing, 19, 176-186.

Stephenson, A. L., \& Yerger, D. B. (2014). Does brand identification transform alumni into university advocates? International Review on Public and Nonprofit Marketing, 11(3), 243-262.

Stinnett, R. C., Hardy, E. E., \& Waters, R. D. (2013). Who are we? The impacts of anthropomorphism and the humanization of nonprofits on brand personality. International Review on Public and Nonprofit Marketing, 10(1), 31-48.

Su, N., \& Reynolds, D. (2017). Effects of brand personality dimensions on consumers' perceived selfimage congruity and functional congruity with hotel brands. International Journal of Hospitality Management, 66, 1-12.

Thomsen, D. K., Olesen, M. H., Schnieber, A., \& Tønnesvang, J. (2014). The emotional content of life stories: Positivity bias and relation to personality. Cognition \& Emotion, 28(2), 260-277.

van Dijk, M., Van Herk, H., \& Prins, R. (2019). Choosing your charity: The importance of value congruence in two-stage donation choices. Journal of Business Research, 105, 283-292.

Wicker, P., \& Breuer, C. (2011). Scarcity of resources in German non-profit sport clubs. Sport Management Review, 14(2), 188-201.

Willems, J., Jegers, M., \& Faulk, L. (2016). Organizational effectiveness reputation in the nonprofit sector. Public Performance \& Management Review, 39(2), 454-475.

Yeung, J. W., Zhang, Z., \& Kim, T. Y. (2018). Volunteering and health benefits in general adults: Cumulative effects and forms. BMC Public Health, 18(1), 1-8.

Zhang, H., Guan, L., Qi, M., \& Yang, J. (2013). Self-esteem modulates the time course of self-positivity bias in explicit self-evaluation. PLoS One, 8(12), e81169.

Zogaj, A., Tscheulin, D. K., Lindenmeier, J., \& Olk, S. (2020). Linking actual self-congruence, ideal selfcongruence, and functional congruence to donor loyalty: The moderating role of issue involvement. Journal of Business Economics. https://doi.org/10.1007/s11573-020-01006-9.

Zogaj, A., Tscheulin, D. K., \& Olk, S. (2021). Benefits of matching consumers' personality: Creating perceived trustworthiness via actual self-congruence and perceived competence via ideal self-congruence. Psychology and Marketing. https://doi.org/10.1002/mar.21439.

Publisher's note Springer Nature remains neutral with regard to jurisdictional claims in published maps and institutional affiliations. 